\title{
Behavioral Tactics for Reinstating Natural Breathing in Infants with Tracheostomy
}

\author{
Logan Wright ${ }^{[14]}$, Arthur Nunnery, Berkley Eichel, and Robert Scott \\ Departments of Pediatrics and Otorhinolaryngology, Children's Memorial Hospital, \\ University of Oklahoma School of Medicine, Oklahoma City, Oklahoma, USA
}

\section{Extract}

Two 8-month-old, Caucasian male infants with long-standing difficulties in decannulation following tracheostomy were subjected to a program designed to facilitate a return to normal breathing. Both infants had previously experienced numerous unsuccessful attempts at decannulation; they possessed a tolerance for breathing normally for a period of less than five minutes. After a 3-week behaviorial treatment program, their ability to breathe normally rapidly improved when the tracheostomy cannula was occluded. At the end of treatment, the patients progressed from a tolerance of less than 5 minutes to 36 continuous hours of occlusion, and the cannula was successfully removed without complication. The patients have fared well since that time.

\section{Speculation}

It is hypothesized that the principles of conditioning and behavioral modification applied in this investigation offer a practical, effective solution to the problem of decannulation following tracheostomy. The unique advantages of the techniques employed include: (1) The patient is better prepared for decannulation by virtue of having the ability to breathe normally before such procedures are attempted, and (2) the longer periods of independent breathing by the patient indicate when decannulation may occur with predictable success.

\section{Introduction}

This report describes behavioral procedures used in the treatment of chronic tracheostomy addiction in two 8-month-old infants. The term addiction is used to imply a long-standing tracheostomy and apparent psychological dependence on breathing through a cannula. The investigation reflects the collaborative, multidisciplinary approach to the problem by investigators in the fields of pediatrics, otolaryngology, and psychology.

Difficulties in delayed decannulation or addiction result when a patient is apparently physiologically ca- pable of giving up his artificial airway, but is unable to do so. In such cases, when the cannula is removed, the patient becomes cyanotic, manifests labored breathing and deep substernal retractions, and may even lose consciousness.

Addiction is less prevalent today than in the past, principally because of the decrease in diseases such as polimyelitis and diphtheria, when tracheostomy is frequently required. Problems associated with decannulation have persisted over the years, however, with no discovery of any satisfactory solution. There are reports of addiction lasting for as long a period as 12 years [10]. A persistent addiction has debilitating effects on 
development of speech, physical and motor performance, and interpersonal and social skills; moreover, it may be fatal. Venables [12] reported four deaths as a result of problems arising from decannulation in 12 children. Thus, addiction represents a debilitating and potentially dangerous condition for the patient.

Difficulty in removing a tracheostomy cannula has been found to be due chiefly to two major factors, young age (first few weeks or months of life) at the time of surgery and the long interval of time between tracheostomy and the first attempt at decannulation [7]. The younger the child and the longer time the cannula is inserted, the poorer the prognosis for successful decannulation.

Most attempts to eradicate addiction rely on the passage of time and the growth and maturation of the child [3]. Use of special surgical techniques during initial introduction of the cannula has been suggested as a means of subsequently reducing the chance of addiction [7]. Groves and MARES [6] reported a method of graduated occlusion of the tracheostomy cannula, 'corking', for progressively longer periods of time prior to attempting removal, but concluded that this method was generally unsatisfactory. A fourth method uses a facilitating apparatus such as a plastic cannula [6]. This apparatus is presumed to perform a function similar to that of the ordinary cannula, but is given up more easily by addicted patients. Another study [5] of the difficult problems of decannulation reported four infants who were successfully extubated by substituting an indwelling intralaryngeal portex (polyvinyl) tube inserted through the nose under general anesthesia; however, a minimum of five to seven days of intensive nursing care was needed prior to attempting removal of this substitute airway. In addition, one of the four patients required five and one-half weeks of such care before the nasotracheal tube was successfully removed. Failure to solve this problem by physical or surgical means led the investigators to suspect that it may have been one of learning and behavior, in which case, behavioral treatment procedures might have been more effective.

Conditioning of autonomically mediated and involuntary behavior began in 1903, when Ivan Pavlov conditioned the salivating reflex of a dog. In recent years, conditioning procedures have been modified for application to problems encountered by pediatricians and include successful treatment of disorders such as vomiting [13], hysterical blindness [2], tics [1], and psychogenic seizures [4]. KimmeL [8], in his review, concluded that heart rate, vasomoter reflexes, salivation, intestinal contractions, and galvanic skin responses are susceptible to conditioning. This review was encouraging because addiction appears to be an involuntary or autonomically mediated response. Proce- dures derived from conditioning might, then, assist in reinstating normal breathing.

\section{Case Reports}

The patients were two 8-month-old, Caucasian male infants with persistent tracheostomy addiction. One infant had required tracheostomy at 7 weeks of age because of encephalitis and respiratory arrest from which there were no demonstrable sequellae. From the time he was 12 weeks of age, numerous attempts of decannulation had been unsuccessful. Each attempt had resulted in cyanosis and deep retractions requiring almost immediate reintroduction of the cannula. The second patient had required tracheostomy at one week of age because of suspected laryngeal webbing. Subsequently, laryngoscopy and bronchoscopy revealed normal structures. Numerous attempts to remove the cannula, beginning at 12 weeks of age, were unsuccessful.

\section{Methods}

In order to solve the problem of decannulation by use of behavioral conditioning techniques, the child was exposed to pleasurable events while he was breathing normally, but to no such events while he was breathing through the cannula. The first step consisted of determining what events were thought to be pleasurable for each patient. The nurses were asked to observe what events provided maximum gratification. Eating and drinking were excluded inasmuch as it was necessary for the patients to breathe through the cannulae during food and drink intake. Patient No. 1 was reported to derive maximum pleasure from moving about in his walker, 'rough-housing' with his father, his bath, tender loving care and other social contacts with nurses and others, and playing with objects and toys. Patient No. 2 was reported to show pleasure primarily from tender loving care and other social contacts and from contact with toys and other objects.

Next, a decision was made to occlude the cannulae for three periods each day. During these periods, each patient was given a maximum amount of his special type of attention. While the patients were breathing through their unoccluded cannulae, they were isolated from people and play objects. The following situations were exceptions : feeding, suctioning of tracheostomies, and changing diapers. Some investigators [9, 11] familiar with research concerning the detrimental effects of sensory and social deprivation may question the ethics of employing isolation; however, the danger of continued addiction seemed considerably greater than 
Table I. Approximate length of time for each of three daily occlusions of the tracheostomy cannula for successive days of the three-week conditioning program

\begin{tabular}{lccccc}
\hline Day & $\begin{array}{c}\text { Length of time } \\
\text { occluded each } \\
\text { session }\end{array}$ & Day & $\begin{array}{c}\text { Length of time } \\
\text { occluded each } \\
\text { session }\end{array}$ & Day & $\begin{array}{c}\text { Length of time } \\
\text { occluded each } \\
\text { session }\end{array}$ \\
\hline 1 & $3 \mathrm{~min}$ & 8 & $25 \mathrm{~min}$ & 15 & $1 \mathrm{~h} 30 \mathrm{~min}$ \\
2 & $5 \mathrm{~min}$ & 9 & $30 \mathrm{~min}$ & 16 & $2 \mathrm{~h}$ \\
3 & $8 \mathrm{~min}$ & 10 & $35 \mathrm{~min}$ & 17 & $2 \mathrm{~h} 30 \mathrm{~min}$ \\
4 & $11 \mathrm{~min}$ & 11 & $40 \mathrm{~min}$ & 18 & $3 \mathrm{~h}$ \\
5 & $14 \mathrm{~min}$ & 12 & $50 \mathrm{~min}$ & 19 & $4 \mathrm{~h}$ \\
6 & $17 \mathrm{~min}$ & 13 & $1 \mathrm{~h}$ & 20 & $5 \mathrm{~h}$ \\
7 & $20 \mathrm{~min}$ & 14 & $1 \mathrm{~h} 15 \mathrm{~min}$ & 21 & $36 \mathrm{~h}$ continuous \\
\hline
\end{tabular}

the possible ill effects of isolation. There is little evidence of significant or lasting impairment as a result of isolation of the degree and duration employed in this study.

On the first day of treatment, approximately thirty minutes following each of three feedings, the cannulae were occluded for three minutes. The duration of the occlusion periods was increased daily according to the schedule shown in table I. During these periods, patients received as much attention as possible. When the cannula was not occluded, the patients were kept in a room with the window shades down and the door closed. A small opening approximately 0.5 inch in diameter in one window permitted the nurse to watch the infants without being seen. The cribs contained no toys or other objects for play. On the first day, it was noted that Patient No. 1 was playing with his bootie strings. These were taped down to prevent the infant from playing while breathing through his cannula.

Patient No. 1 had an 0 sized tracheostomy tube that permitted limited air passage around the tube during occlusion periods. Immediately prior to treatment, however, Patient No. 2 was fitted with a smaller 00 sized tube with a hole drilled at the angle of the cannula. Thus, in this patient, larger amounts of air could pass between the tube and the walls of the trachea and additional air could pass through the tube and out of the nose and/or mouth through the hole drilled at the angle of the cannula. The smaller tube apparently made breathing somewhat easier for patient No. 2 during occlusion periods; however, the dissimilar cannulae did not produce any detectable differences in the progress of the two patients.

\section{Results}

Cyanosis, labored breathing, and deep retractions accompanied the initial occlusion periods on the first day.
There was some question as to whether the periods would have to be cut short, but cyanosis and retractions decreased significantly with each successive occlusion. By the end of the first week, neither patient exhibited cyanosis during occlusion, and retractions were either mild or absent. By the middle of the second week, the patients appeared to be more uncomfortable during isolation than during periods of occlusion. They ceased their previous patterns of crying at the time their cannulae were occluded, but began crying when the occluding tape was removed, apparently anticipating a return to isolation. During the last week of treatment, both patients manifested a complete absence of cyanosis and only very occasional mild retractions, although the time of each period of occlusion was increased by thirty minutes or one hour per day. At this time, the patients were offered small amounts of food and liquid during periods of occlusion. Initially, both patients manifested difficulty and awkwardness, but by the end of one week, both were able to ingest all food and liquid during times of occlusion.

On the twentieth day, each period of occlusion lasted five hours, for a total of 15 hours. The program had been planned so that the 5-hour occlusion periods would occur on a Saturday, and the patients were occluded continuously from $7.00 \mathrm{a} . \mathrm{m}$. until $5.00 \mathrm{p} . \mathrm{m}$. At 8.00 p.m., the patients were occluded until 8.00 a.m. on the following Monday, at which time, decannulation was performed without complications. Both patients fared extremely well during the subsequent nine months and exhibited no respiratory distress, difficulties in deglutination, or other problems thereafter.

\section{Discussion}

The apparent successful treatment reported in this study suggests that strategic use of attention and isola- 
tion, in conjunction with progressively increased periods of cannula occlusion, can be effective in treating tracheostomy addiction in young children.

One impressive aspect of this treatment is the opportunity it affords for observing daily behavioral changes. The consistently progressive decline of cyanosis and retractions during the lengthened periods of occlusion showed that normal breathing was being reinstated. Another advantage of this procedure is that it predicts decannulation success. One can determine the likelihood of success prior to attempted decannulation. If a patient has been observed to progress in a systematic manner, one may anticipate, with a high level of confidence, the success of the desired procedure. Conversely, if decannulation is attempted before the patient has demonstrated a capacity to breathe normally for extensive periods of time, there would be little evidence that would enable the physician to predict the success of decannulation or even to determine when to attempt such a procedure.

This clinical trial has not conclusively demonstrated that the differential attention programmed to accompany regularly scheduled periods of cannula and laryngeal breathing was essential to success of the treatment. Future attempts to refine the procedure should empirically determine the functional relation of heightened attention and isolation to the progressive adaptation of individual infants to laryngeal breathing. Perhaps isolation does not function adversely for all infants. If it can be shown that differential attention within the ward environment is sufficient to facilitate adaptation, then isolation may be unnecessary; however, if cannula breathing must necessarily be accompanied by adverse conditions, an array of substitutes for isolation could be determined empirically. Possibly, light versus darkened conditions would function as well as differential attention in facilitating a return to normal breathing.

Variations in the schedule of periods of occlusion should also be examined. It is possible that certain infants might progress more rapidly than our schedule permitted. Occasionally, an occlusion period might be doubled to determine if adaptation could be hastened.

\section{Summary}

Two infants with long-standing difficulties in decannulation following tracheostomy were treated by techniques derived from behavioral conditioning. These techniques proved to be successful in accomplishing extremely difficult decannulation and offer certain advantages over other techniques. The ability of the patient to breathe through normal channels is demonstrated prior to the time decannulation is attempted and, in addition, the progressively longer periods of independent breathing indicate when decannulation should occur with predictable success.

\section{References and Notes}

1. BARRETT, B.H.: Reduction in rate of multiple tics by free operant conditioning methods. J.nerv. ment. Dis. 135: 187-195 (1962).

2. Brady, J.P. and Lind, D. L.: Experimental analysis of hysterical blindness: operant conditioning techniques. Arch.gen. Psychiat. 4: 331-339 (1961).

3. CRooks, J.: Non-inflammatory laryngeal stridor in infants. Arch. Dis. Childh. 29: 12-17 (1954).

4. GARDNER, J.E.: Behavior therapy treatment approach to a psychogenic seizure case. J.cons. Psychol. 31: 209-212 (1967).

5. Greenberg, L.H.; Davenport, H.T. and Shimo, G. : Method for difficult decannulation in children. Arch. Otolaryng. 81: 72 (1965).

6. Groves, J. and Mares, A.: A means of effecting decannulation after tracheostomy. J. Laryng. and Otol. 77: 937-942 (1963).

7. JACKSON, B.: Management of the tracheostomy in cases of tetanus neonatorum treated with intermittent positive pressure respiration. J. Laryng. 77: 541-554 (1963).

8. KrmmeL, H.D.: Instrumental conditioning of autonomically mediated behavior. Psychol.Bull. 5: 337-345 (1967).

9. Murphy, L. B.: Social behavior and child personality (Columbia Univ. Press, N.Y. 1937).

10. SNow, J. B.: Personal communication, 1967.

11. Sprtz, R.A.: Hospitalism: An inquiry into the genesis of psychiatric conditions in early childhood; in: The psychoanalytic study of the child (ed. O. FenicheL), vol. 1, pp. 53-74 (International Universities Press, New York 1945).

12. Venables, A.W.: Tracheostomy in childhood. Med.J.Austr. 17: 141-143 (1959).

13. Wolf, M. M.; Birnbrauer, J.S.; Williams, T. and LAWLER, J.: A note on apparent extinction of the vomiting behavior of a retarded child; in: Case studies in behavior mod. (ed. LeONARD ULLMAN and Leonard Krasner), Ch.48, pp.364-366 (Holt, Rinehart + Winston 1965).

14. Requests for reprints should be sent to: LogAN, Wright, Ph.D., Children's Memorial Hospital University of Oklahoma Medical Center, 800 N.E. 13th Street, Oklahoma City, Okla. 73104 (USA). 